Research Article

\title{
Landslide Failure Mechanisms of Dispersive Soil Slopes in Seasonally Frozen Regions
}

\author{
Lixiang Wang $\mathbb{D}^{1,2}$ Xiaoming Yuan $\mathbb{D}^{1},{ }^{1}$ and Miao Wang ${ }^{2,3}$ \\ ${ }^{1}$ Institute of Engineering Mechanics, Key Laboratory of Earthquake Engineering and Engineering Vibration, \\ China Earthquake Administration, Harbin, Heilongjiang 10080, China \\ ${ }^{2}$ Heilongjiang Provincial Key Laboratory of Engineering Permafrost in Seasonal Permafrost Area, Harbin, \\ Heilongjiang 10086, China \\ ${ }^{3}$ Harbin University of Science and Technology, Harbin, Heilongjiang 10086, China
}

Correspondence should be addressed to Xiaoming Yuan; yxmiem@163.com

Received 11 June 2020; Revised 24 November 2020; Accepted 5 December 2020; Published 18 December 2020

Academic Editor: Hui Yao

Copyright (C) 2020 Lixiang Wang et al. This is an open access article distributed under the Creative Commons Attribution License, which permits unrestricted use, distribution, and reproduction in any medium, provided the original work is properly cited.

Hydraulic projects with dispersive soil in seasonally frozen regions are susceptible to landslide failures. The mechanism of such landslide failures has not been fully understood thus far; therefore, it was investigated in this study by using on-site surveys, laboratory tests, and theoretical calculations. The results showed that the landslides of dispersive soil in seasonally frozen regions could be categorized as shallow-seated landslides and deep-seated landslides. The preconditions for landslide occurrence were soil mass looseness and cracks, caused by freeze-thawing. The degradation of dispersive soil led to a rapid influx of water into the soil. The reason for shallow-seated landslides was that the numerous sodium ions present in the soil mass dissolved in water and damaged the soil structure, resulting in a substantial reduction in shear strength. The reason for deep-seated landslides, however, was the erosion due to rainfall infiltration after the shallow-seated landslides caused tensile cracks at the top of the slope, leading to soil instability. Landslide failures occurred when the dispersing soil slope underwent freeze-thawing and saturated soaking. The sliding surface was initiated at the top of the slope and gradually progressed to the bottom along the interface between the soil layers.

\section{Introduction}

Dispersive soil is widely distributed across the world. The United States, Spain, Australia, South Africa, Iran, and China have numerous water conservancy and road construction projects based on dispersive soil [1-5]. In Northwest China, North China, and the Northeast Songnen Plain, a large number of water conservancy and road projects were built with dispersive soil, such as the Xinjiang Irtysh River Water Conservancy, Ningxia Majiashu Reservoir, Heilongjiang Nierji Reservoir, Nen River Diversion of the Shuangyanghe Reservoir, Anzhao New River, and Zhaolan New River. Hence, there is a need to focus on the stability of dispersive soil slopes in seasonally frozen regions caused by freeze-thawing, soaking, and rainfall.
The common damage in dispersive soil projects includes erosion damage, seepage piping damage, frost heave damage, and landslide damage. Erosion damage is widespread around the world, among which large areas of gullies appear in the Northeast Plain of China and the Australian grasslands. Seepage piping damage mainly occurs on the side of the dam body of a dispersive soil dam and the shoulder of a road subgrade. Figure 1(b) shows the piping damage of Blackman Creek Dam in the United Kingdom. The frost heave damage of dispersive soil mainly occurs at the locations of buildings and channel slopes in Alpine regions, such as the northern United States, the Calgary region of Canada, southern Australia, and northeastern China. Figure 1(c) shows the frost heave damage of dispersive soil channels on the slopes in Northeast China. Dispersive soil landslide damage mainly occurs in the position of the channel slope 


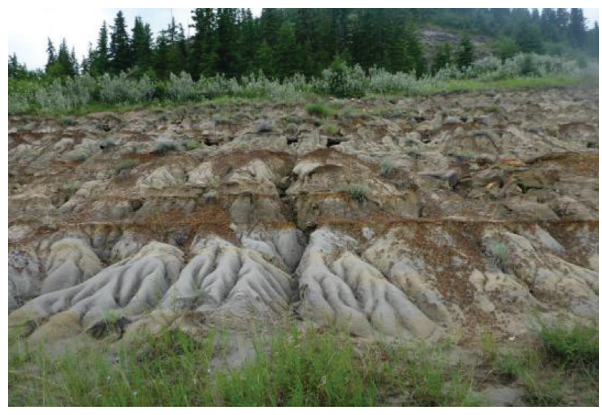

(a)

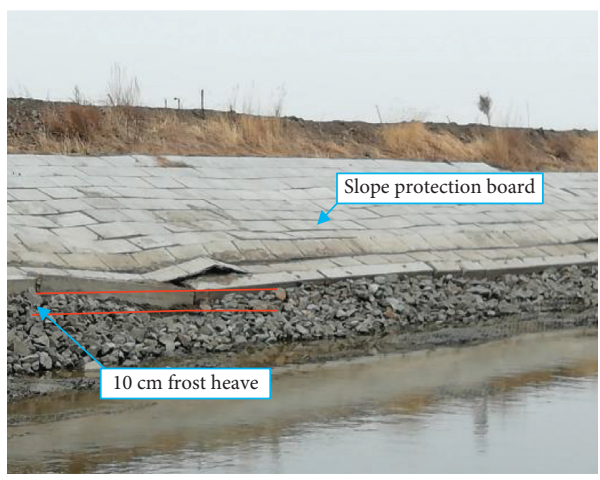

(c)

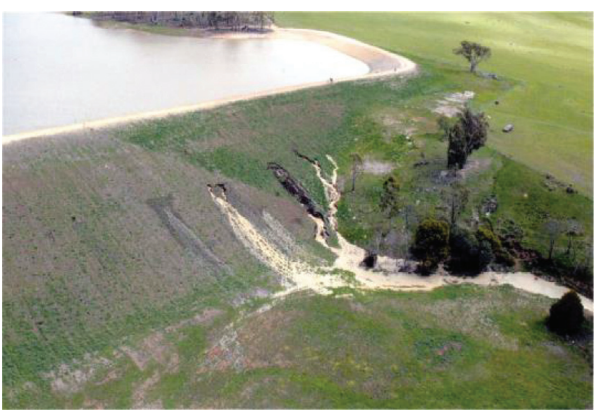

(b)

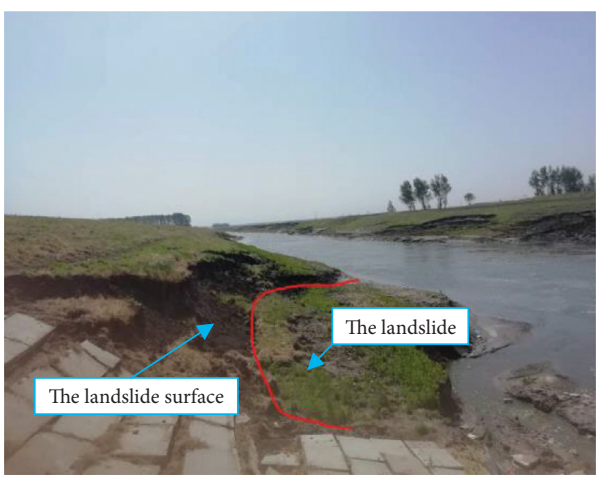

(d)

Figure 1: Main failure types of dispersive soil projects. (a) Erosion failure of dispersive soil (Canada), (b) seepage pipe failure of dispersive soil (Blackman Creek Dam), (c) frost heave failure of dispersive soil, and (d) landslide failure of dispersive soil.

where the water is passed through a seasonally frozen soil area. Figure $1(\mathrm{~d})$ shows the landslide damage of the water channel slope in Northeast China.

A relatively adequate amount of research has been conducted on the identification and modification of dispersive soil, both in China and abroad. However, few studies have been conducted on landslide failures of dispersive soil slopes [4, 6-15]. Sun [16] and Tong [17] studied the mechanisms and causes of landslides on the dispersive soil slopes of the trunk canal channel in the Heilongjiang Nen River diversion project. However, both of these studies were descriptive studies and were not supported by reliable data. Liu et al. [18] studied different types of frost damage prevention techniques, particularly for the failure modes and frost heave characteristics of dispersive soil slopes in seasonally frozen regions, but their findings have not been corroborated by other relevant studies.

A strength indicator is typically used for landslide stability calculations under saturated, consolidated undrained conditions and normal indoor temperatures. However, factors such as freeze-thawing and water immersion, which substantially affect dispersive soil strength, are not taken into account. In this research, we studied the mechanism of the destruction of dispersive soil slopes in seasonally frozen regions by using data from on-site surveys, laboratory tests, and theoretical calculations. We explored some of the causes of landslides and provided theoretical guidance on the treatment of dispersive soil slopes in seasonally frozen regions to prevent landslides. The special properties of dispersive soil were explored, the mechanism causing the landslide of the dispersive soil slope was determined, and the effect of freezing and thawing on the landslide of the dispersive soil slope was explained.

\section{Fundamental Types of Landslide Failure of Dispersive Soil Slopes}

Dispersive soil slopes in seasonally frozen regions are often affected by rainfall, freeze-thawing, and soaking, which cause erosions and landslides. Figure 2 shows the site of destruction of the slope due to the landslides of the Zhaolan New River channel project in Daqing City, Heilongjiang Province (Northeast China). Landslides over areas of tens of square kilometers during flooding seasons cause huge losses.

The on-site survey showed that two types of landslides, shallow and deep, appeared on the slope of this channel. Figure 2(b) presents a shallow-seated landslide of the dispersive soil slope; i.e., the body of the landslide had a shallow structure. The shallow-seated landslide of this channel was widely distributed across the slope. Figure 2(c) demonstrates a deep-seated landslide of the dispersive soil slope. The depth of the landslide body was more than that of the shallowseated landslide, and the landslide occurred throughout the channel. According to a preliminary analysis, different mechanisms lead to the formation of the two types of landslides.

Table 1 shows the rivers and reservoirs built from dispersive soil in the study area. The length of the rivers and the 


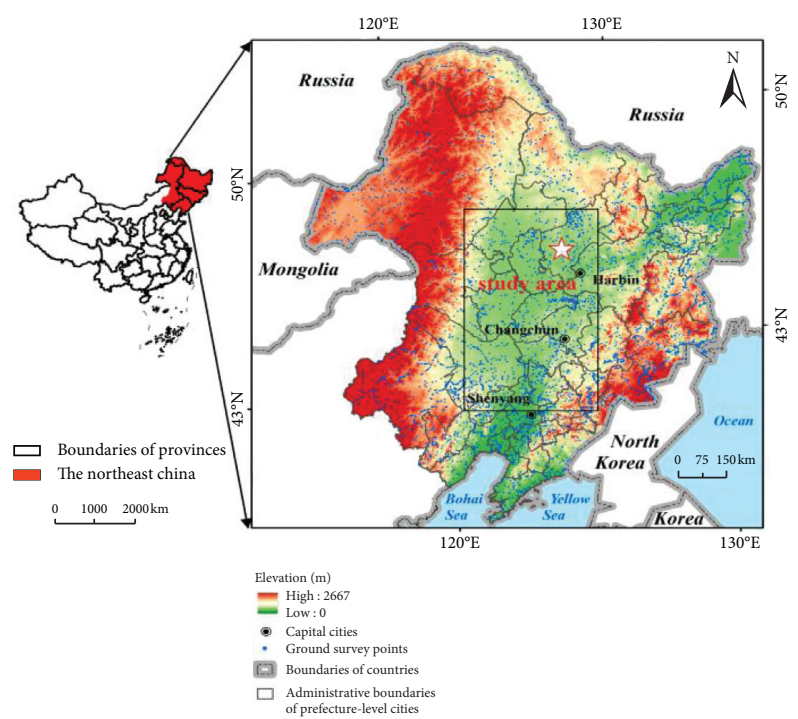

(a)

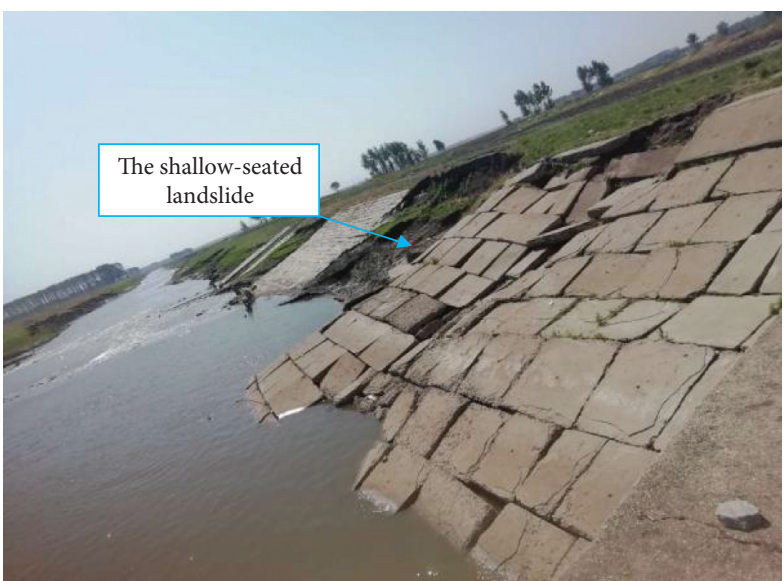

(b)

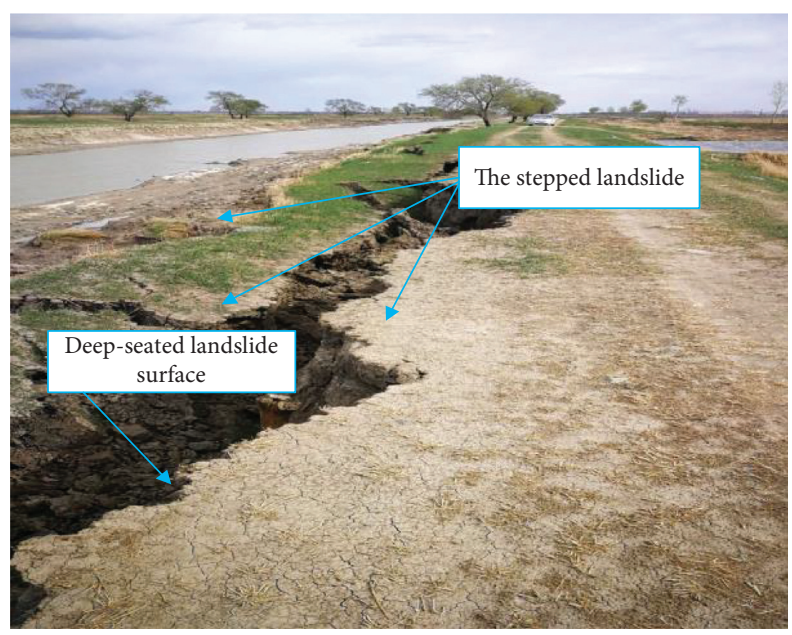

(c)

Figure 2: Types of landslides of dispersive soil slopes (Daqing City, Northeast China). (a) Area and location of the site of destruction (Daqing City, Northeast China), (b) shallow-seated landslide of dispersive soil, and (c) deep-seated landslide of dispersive soil.

TABLE 1: The rivers and channels damaged by landslide failure of dispersive soil slopes.

\begin{tabular}{lccc}
\hline Location & Name of rivers & Rivers length $(\mathrm{km})$ & Dispersive soil slopes length $(\mathrm{km})$ \\
\hline Daqing City, Suihua City & Zhaolan New River & 103.8 & 70 \\
Daqing City & Anzhao New River & 108 & 94 \\
Daqing City, Changchun City & Shuangyange River & 95 & 65 \\
Jilin, Heilongjiang (province) & Nen River & 1370 & No statistical data \\
Daqing City & Longhupao Reservoir channel & 97.1 & 54 \\
Qiqihaer City & Wuyuer River & 203 & 81 \\
Daqing City & Nanyin Reservoir & - & No statistical data \\
Daqing City & Pangtoupao store floodwater area & 107 & 84 \\
Qiqihaer City & Beiyin Reservoir channel & 245 & 161 \\
\hline
\end{tabular}

dispersive soil slopes is listed in Table 1. These rivers are located in Daqing City (Heilongjiang Province), Qiqihar City (Heilongjiang Province), and Changchun City (Jilin Province). Therefore, these rivers and channels are subject to landslide damage to dispersive soil slopes. From the statistical data in Table 1, 50\% to $90 \%$ of the dispersive soil slopes of rivers and channels are likely to be damaged by landslides. Unlike other studies on the dispersive soil, this article is the first to report a study on dispersive soil slope landslides. This dispersive soil landslide damage is also 
widespread in the seasonal frozen areas such as the Mississippi River basin (the United States), Calgary (Canada), and Queensland (Australia) [19, 20].

We emphasized the importance of the shear strength of dispersive soil in studying the mechanism of dispersive soil slope landslides. Regarding the shear strength of dispersive soil, a test study was conducted in Section 3 and landslides reason of dispersive soil slopes is discussed in this section.

\section{Shear Strength of Dispersive Soil in Seasonally Frozen Regions}

To study the landslide failure mechanisms of dispersive soil slopes, it was necessary to first investigate the shear strength of the dispersive soil under conditions such as freezethawing and soaking.

3.1. Method. The Zhaolan New River in Heilongjiang Province was considered for this study. A landslide failure occurred when the channel experienced freeze-thawing and soaking after the construction had been completed. The thickness of the newly filled layer was $5.5 \mathrm{~m}$, and the depth of the frozen soil in the area was approximately $1.5 \mathrm{~m}$ according to the monitoring data. Hence, the dispersive soil in the filled layer was divided into a frozen soil layer and a nonfrozen soil layer. Because of the occurrence of the landslide on the site, the soil layer was destroyed, and samples of the original soil could not be obtained for analysis with the currently available technologies and methods. Therefore, the authors obtained samples of the available on-site soil and restructured it (i.e., by controlling the water content and dry density to replicate the conditions during construction) to estimate the shear strength of the soil mass after freeze-thawing and soaking during construction. This method of approximation has also been used by several other researchers.

For the cold natural environmental conditions at high altitudes in Northeast China, newly filled nondispersive soil was compacted during construction to meet the design codes. In general, dispersive soil has a strong water retention capacity and a low penetration coefficient and is thus not easy to drain. Hence, after compaction in winter, a small amount of settlement deformation might occur over a short period. However, this deformation rate was insignificant as compared to the deformation rate of the frost heave-thaw settlement of the dispersive soil. Thus, the use of a consolidation indicator might result in overlooking the significant effect of the frost heave-thaw settlement on the physical and mechanical properties of dispersive soil. Hence, a nonconsolidation indicator was used for the newly filled layer. As the state of the old embankment layer resulted in a long settlement time of the nondispersive soil, it was more appropriate to use the consolidation indicator for samples of the original soil.

3.2. Test Control and Devices. Table 2 shows the physical properties of the dispersive soil of the Zhaolan New River. The composition of the soil is silty clay with a low liquid limit. It has a maximum dry density of $1.66 \mathrm{~g} \cdot \mathrm{cm}^{-3}$ and an optimum water content of $20.2 \%$. The laboratory tests, including crumb test, pinhole test, chemical test (exchangeable sodium percentage and sodium adsorption ratio), and double hydrometer test, showed that the soil was dispersive soil, as presented in Table 3 . The results of these tests are presented in Table 4 . In the tests, air-dried dispersive soil was screened through a sieve with a grid of $2 \mathrm{~mm}$, and the soil samples were then stored with a $20 \%$ water content for $24 \mathrm{~h}$. Tests were conducted for soil dry densities of $1.33 \mathrm{~g} \cdot \mathrm{cm}^{-3}, 1.43 \mathrm{~g} \cdot \mathrm{cm}^{-3}, 1.53 \mathrm{~g} \cdot \mathrm{cm}^{-3}$, and $1.63 \mathrm{~g} \cdot \mathrm{cm}^{-3}$. Three types of preliminary treatments were conducted to obtain different states for the samples: the natural state (20\% water content), freeze-thaw state, and the state after saturated soaking for $72 \mathrm{~h}$ following freezethawing. We placed the soil samples that needed freezethaw and freeze-thaw-soaking into the shear box and then placed the soil samples into the low-temperature test box. The initial temperature of the low-temperature test box was $0^{\circ} \mathrm{C}$, and the temperature was controlled to cool down at a rate of $-4^{\circ} \mathrm{C} / \mathrm{h}$. The surface of the soil samples was covered with a plastic film to prevent water loss. After reaching the freezing time, we adjusted the temperature to the melting temperature and took the samples out after reaching the melting time. The freezing time and the thawing time were $48 \mathrm{~h}$ and $12 \mathrm{~h}$, respectively, and the freezing temperature and the thawing temperature were $-20^{\circ} \mathrm{C}$ and $20^{\circ} \mathrm{C}$. Next, we placed all the soil samples into the electric strain direct shear apparatus and added distilled water to the soil samples that needed to be soaked after freezing and thawing to completely immerse the soil samples; the soaking time was $72 \mathrm{~h}$.

The electric strain direct shear apparatus used for this research is presented in Figure 3. Because of the working conditions of the dispersive soil slope in the flood season, nonconsolidation undrained direct shear tests were conducted in this study. The tests were conducted after meeting the requirements shown in Table 4 . The vertical pressures tested were $50 \mathrm{kPa}, 100 \mathrm{kPa}, 200 \mathrm{kPa}$, and $400 \mathrm{kPa}$. The other control conditions for the tests were based on the control requirements in "Standard for Geotechnical Test Methods" GB/T50123-1999 [21].

3.3. Test Results. According to the Mohr-Coulomb strength theory, the shear strength of soil is divided into cohesive strength and frictional strength. Nevertheless, the actual strength mechanisms and the influencing factors of the soil are considerably complicated, and thus, the manifestation of soil strength is often inconsistent with the expected mechanism [22]. In this work, the variation of shear strength under different working conditions was analyzed, while the cohesive force and the internal friction angle were obtained separately in the calculation of slope stability. Figure 4 shows the variation of the shear strength of the soil sample with dry density under different test conditions. In Figure 4, W20D1.33 refers to the initial water content of $20 \%$ and the initial dry density of $1.33 \mathrm{~g} \cdot \mathrm{cm}^{-3}$ (as shown below). For soil samples with the same initial water content, i.e., the natural water content, but with different initial dry densities, the 
TABle 2: Physical properties of dispersive soil.

\begin{tabular}{lcccc}
\hline Specific gravity $G_{s}$ & Liquid limit $w_{L}$ & Plastic limit $w_{P}$ & \multicolumn{2}{c}{ Grain composition $(\mathrm{mm})$} \\
& & & $>0.075$ & $0.075 \sim 0.005$ \\
\hline 2.70 & 36 & 21 & 33 & 40 \\
\hline
\end{tabular}

TABLe 3: Dispersibility of dispersive soil.

\begin{tabular}{lccccccc}
\hline Crumb & $\begin{array}{c}\text { Double } \\
\text { hydrometer test }\end{array}$ & $\begin{array}{c}\text { Pinhole test } \\
\text { Dispersion ratio } \\
(\%)\end{array}$ & $\begin{array}{c}\text { Dry density } \\
\left(\mathrm{g} \cdot \mathrm{cm}^{-3}\right)\end{array}$ & $\begin{array}{c}\text { Final head } \\
(\mathrm{mm})\end{array}$ & $\begin{array}{c}\text { Pinhole } \\
\text { size }\end{array}$ & $\begin{array}{c}\text { Final flow } \\
(\mathrm{ml} / \mathrm{s})\end{array}$ & $\begin{array}{c}\text { Colour } \\
\text { Dispersive }\end{array}$ \\
\hline
\end{tabular}

Notes: ASTM D4647-1993 (USA).

TABLe 4: Shear strength test conditions of dispersive soil.

\begin{tabular}{lcccc}
\hline $\begin{array}{l}\text { Water content } \\
(\%)\end{array}$ & $\begin{array}{c}\text { Dry density } \\
\left(\mathrm{g} \cdot \mathrm{cm}^{-3}\right)\end{array}$ & $\begin{array}{c}\text { Freezing temperature/thawing temperature } \\
\left({ }^{\circ} \mathrm{C}\right)\end{array}$ & $\begin{array}{c}\text { Freezing time/thawing time } \\
(\mathrm{h})\end{array}$ & $\begin{array}{c}\text { Soaking time } \\
(\mathrm{h})\end{array}$ \\
\hline 20 & $1.33,1.43,1.53,1.63$ & $-20 / 20$ & $48 / 12$ \\
\hline
\end{tabular}

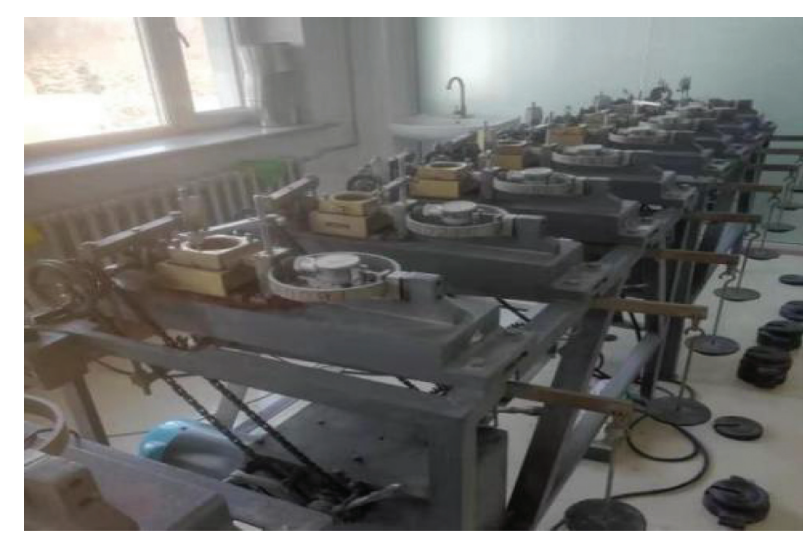

FIgURE 3: Electric strain direct shear apparatus.

shear strength increased with an increase in the dry density, and the trend was similar to that of nondispersive soil.

As the dry density increased, the effect of dry density on the shear strength of soil samples after freeze-thawing was more pronounced. For a lower dry density, the porosity of the soil mass was larger, and the volume change caused by freeze-thawing was offset by the pores of the soil mass. Therefore, the shear strength of the dense soil mass was more susceptible to the effect of freeze-thawing. Several researchers in China and abroad are currently studying the impact of freeze-thawing on soil mass degradation.

Notably, we found that the shear strength dropped substantially after samples of different dry densities were subjected to freeze-thawing and saturated soaking for $72 \mathrm{~h}$. The initial dry density and vertical pressure had little effect on the shear strength. When the dry density and the vertical pressure increased, there was no significant increase in the shear strength of the soil. For the soil sample with an initial dry density of $1.63 \mathrm{~g} \cdot \mathrm{cm}^{-3}$ (for which the compression degree reached $98 \%$ ), the shear strength after freeze-thawing and saturated soaking decreased by 8 to 10 times and did not exceed $30 \mathrm{kPa}$. In this state, it was assumed that the soil mass had lost its bearing capacity and that compacting the soil mass would not alleviate the problem of a dispersive soil landslide. For the dispersive soil slope, the soil mass had a rather low shear strength under its dead-weight stress. Hence, the landslide failure of the dispersive soil slope, as shown in Figure 2, occurred in Heilongjiang Province, Northeast China.

\section{Antisliding Stability of Dispersive Soil Slopes in Seasonally Frozen Regions}

To quantitatively analyze the effect of shear strength reduction on the slope's antisliding stability under different working conditions, the authors used the slice method to calculate the slope stability coefficient of the dispersive soil slopes for different working conditions. 

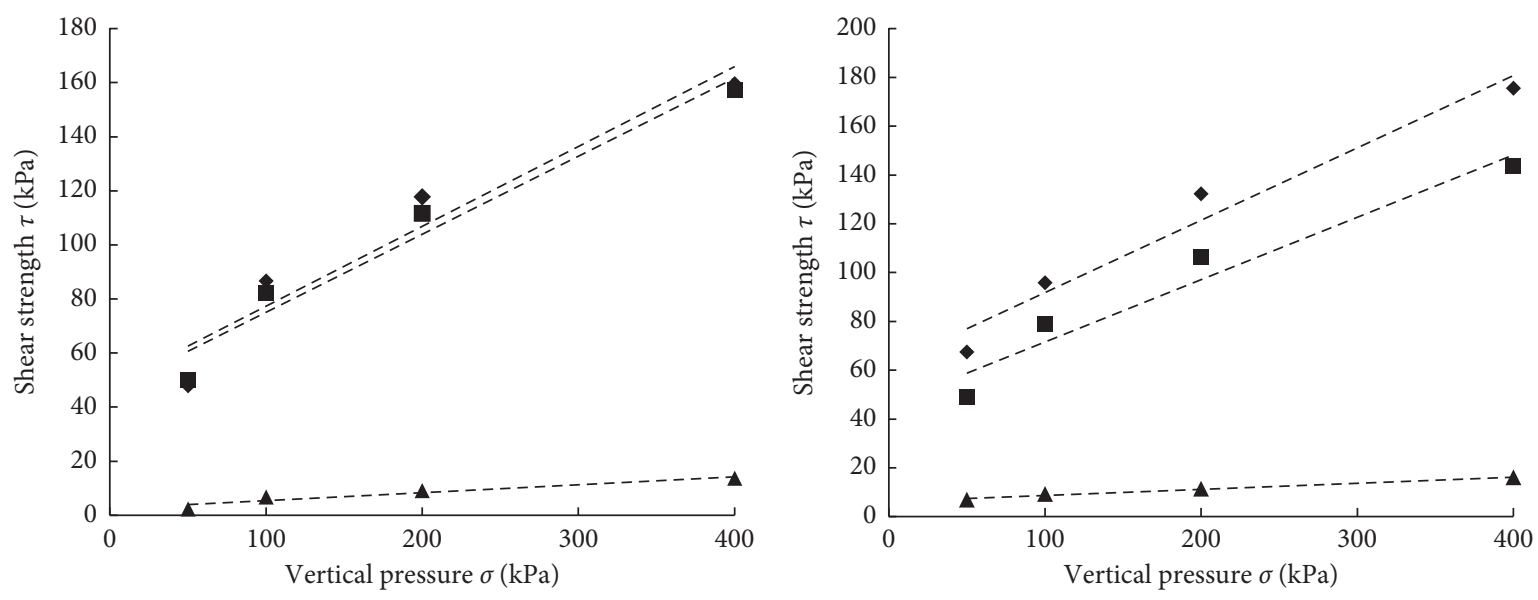

- W20D1.33-natural state

- W20D1.33-freeze-thawing state

A W20D1.33-freeze-thawing and saturated soaking

(a)

W20D1.43-natural state

- W20D1.43-freeze-thawing state

\ W20D1.43-freeze-thawing and saturated soaking

(b)

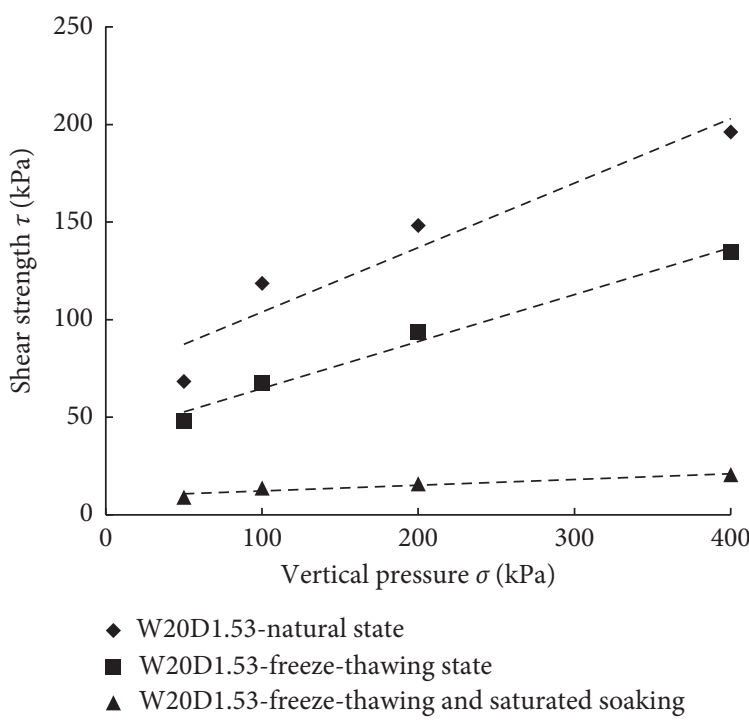

(c)

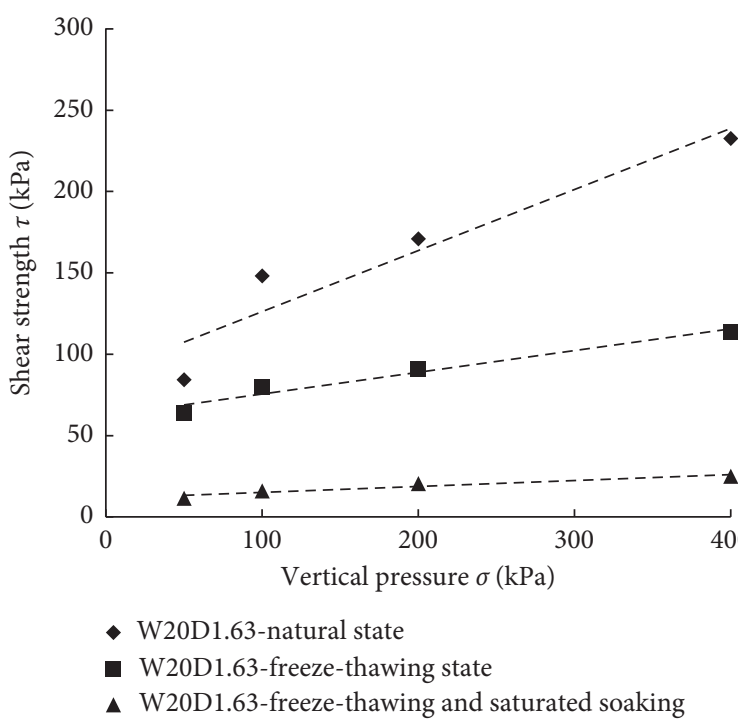

(d)

FIGURE 4: Shear strength of soil samples of different initial dry densities for various test conditions. (a) W20D1.33 sample, (b) W20D1.43 sample, (c) W20D1.53 sample, and (d) W20D1.63 sample.

4.1. Calculation Model. After the construction of a dispersive soil channel was completed, the soil mass of the dam was compacted to meet the design requirements. However, if the channel was exposed to rainfall and supplied by water from other sources, the water inside the soil mass became difficult to drain. This occurred when the groundwater level was high. After cooling down in winter, the groundwater of the dispersive soil channel slope reached the surface layer, driven by the temperature differences, and formed segregated ice. The frost heave deformation within a certain depth of the slope loosened the soil mass. As shown in Figure 5, the seasonally frozen region of the dispersive soil slope was divided into three layers. Layer a was a dispersive soil layer that had been subjected to freeze-thawing and soaking, while layer $b$ was a dispersive soil layer that had not been subjected to freeze-thawing and soaking. Layer c was an old embankment formed from other types of nondispersive soil layers and was mostly composed of silty clay. In winter, when the channel was in the dry season, the phreatic line is represented by the dotted line in Figure 5. Under the conditions of high water levels and rainfall during flood seasons, this layer loosened after freeze-thawing, which allowed the water to enter the soil easily. Hence, the layer became fully saturated, and the phreatic line in the flood season extended along the slope.

Figure 6 demonstrates a simplified calculation model for a section of the Zhaolan New River. The slope of the section was $1: 2.0$. Layer a and layer $b$ increased in height later in the calculation. According to the long-term monitoring data of the soil freezing depth in Daqing City (Northeast China) and the channel design information, the thickness of layers $a, b$, and $\mathrm{c}$ were determined to be $h_{1}=1.5 \mathrm{~m}, h_{2}=4 \mathrm{~m}$, and $h_{3}=10 \mathrm{~m}$, respectively. 


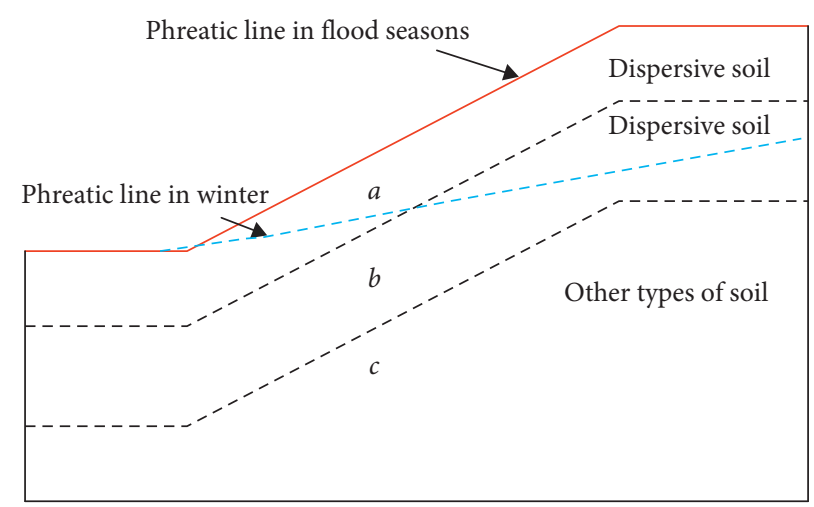

Figure 5: Layers of the dispersive soil slope.

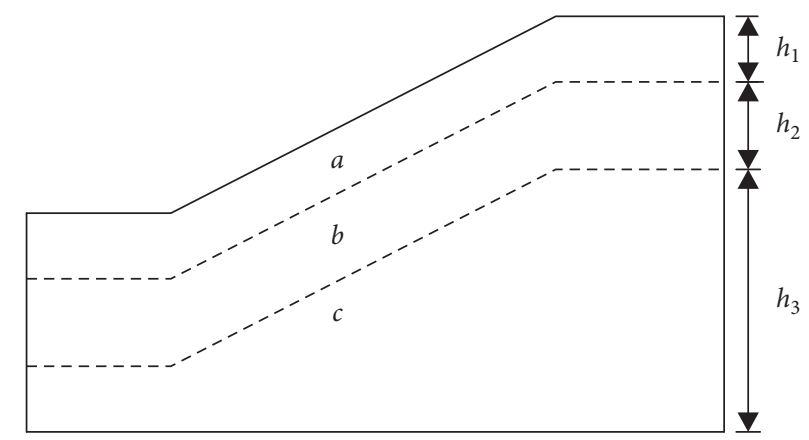

FIGURE 6: Section of dispersive soil for slope stability calculations.

4.2. Working Conditions and Strength Indicator Selection of Dispersive Soil Slopes. To compare and analyze the development mechanisms of the dispersive soil slope stability under different environmental conditions, the following are considered as working conditions:

(1) Condition 1: the dispersive soil slopes undergo freeze-thawing and soaking

Layer a is affected by freeze-thawing and soaking. Accounting for the most adverse effects of water flow and rainfall during the flood season, this layer can be regarded as being fully saturated, and the phreatic line coincides with the slope line. Layer $b$ is also $a$ dispersive soil layer, which is not affected by freezethawing and long-term soaking. Layer $\mathrm{c}$ is the original layer of the old channel, and undrained strength indicator of the original samples according to design and inspection is adopted; the saturation gravity of layer $\mathrm{c}$ is $20.3 \mathrm{kN} \cdot \mathrm{m}^{-3}$. The shear strength indicators of each soil layer are listed in Table 5.

(2) Condition 2: newly completed dispersive soil slopes (no freeze-thawing and soaking)

This was the working condition after the construction of the dispersive soil channel, with no water flow and freeze-thawing in the channel. Both layers a and $b$ used the strength indicator for the soil with a cohesive force $c$ of $70.9 \mathrm{kPa}$ and an internal friction angle $\varphi$ of $18.3^{\circ}$. The strength indicator in Table 5 was also used for layer c. The on-site construction was controlled for an optimal water content of $20 \%$ and a dry density of $1.53 \mathrm{~g} \cdot \mathrm{cm}^{-3}$.

(3) Condition 3: dispersive soil slopes undergo freezethawing (no soaking)

This was the working condition when the construction of the dispersive soil slope was completed. There was no water flow (i.e., water cutoff in winter), and the soil had been subjected to freeze-thawing. Layer a approximated the nonconsolidated undrained strength indicator under the effect of freezethawing, with a cohesive force $c$ of $49.9 \mathrm{kPa}$ and an internal friction angle $\varphi$ of $12.2^{\circ}$. In practice, because of the water migration during freeze-thawing, the actual strength indicator was slightly lower; therefore, the strength indicator was only an approximation. Layers $b$ and $c$ used the strength indicators listed in Table 5.

4.3. Results. On the basis of the working conditions and strength indicators discussed in Section 4.2, the stripe method was used to calculate the antisliding stability coefficient under the various working conditions listed in Table 6.

From the slope stability calculation and analysis, we inferred that when the height of the channel slope was increased during construction (Condition 2), it was deemed to be safe. When the channel underwent freeze-thawing after construction (Condition 3), the channel slope's antisliding 
TABle 5: Shear strength indexes of each layer of soil.

\begin{tabular}{lcc}
\hline Soil layer & Cohesive force $c(\mathrm{kPa})$ & Internal friction angle $\varphi\left(^{\circ}\right)$ \\
\hline$a$ & 7.1 & 2.5 \\
$b$ & 45.3 & 10.5 \\
$c$ & 87.5 & 17.3 \\
\hline
\end{tabular}

TABLE 6: Results of stability analysis.

\begin{tabular}{lcr}
\hline Working condition & Method & Stability coefficient \\
\hline \multirow{2}{*}{ Condition 1 } & Swedish method & 0.880 \\
& Bishop method & 0.883 \\
\multirow{2}{*}{ Condition 2 } & Swedish method & 4.811 \\
& Bishop method & 4.939 \\
\multirow{2}{*}{ Condition 3 } & Swedish method & 3.046 \\
\end{tabular}

stability coefficient was reduced substantially but was still considered to be safe. After being subjected to freezethawing and saturated soaking (Condition 1), the slope stability coefficient of the channel dropped significantly and was considerably lower than its safety coefficient (1.05). The landslide occurred on the slope of the dispersive soil channel, as shown by the sliding surface in Figure 7 . The failure sliding surface was initiated at the top of the slope and developed along the interface of layers. The sliding surface indicated by the dashed line was only a potential sliding surface and did not produce a real landslide.

Due to the influence of freezing and thawing on the shear strength of dispersive soil was relatively small, the stability coefficient of dispersive soil slopes was not greatly reduced. Since freezing and thawing water immersion had a great influence on the shear strength of dispersive soil, the stability coefficient of dispersive soil slopes was greatly reduced, which causes landslides.

\section{Discussion}

We discovered a large area of dispersive soil slope landslide damage at the survey project site. The occurrence of a landslide on such a low-height slope was extremely unusual. Because of the completion of the project, it was initially believed that water erosion caused the slope landslide. A concrete protection board was used to protect the dispersive soil slope and to prevent the water from scouring the slope. However, after a freeze-thaw cycle and channel water flow, the dispersive soil slope produced a large freeze-thaw deformation. The board was lifted up. After the water was passed, the dispersive soil slope slid into the channel together with the concrete protection board; therefore, the factor that caused the dispersive soil slope landslide was the properties of the dispersive soil itself. We conducted experimental research on samples from slopes where landslide damage occurred and conducted shear tests on natural soil samples, soil samples after freezing and thawing, and soil samples after freezing and thawing and soaking. It was found that although freezing and thawing reduced the shear strength of the soil sample, it did not cause landslide damage to the dispersive soil slopes. The shear strength of the soil sample soaked after the dispersive soil underwent freezing and thawing was almost lost, which directly led to the landslide of the dispersive soil slopes.

\subsection{Different Properties of Dispersive Soil and Nondispersive} Soil. The special characteristic of dispersive soil was the root cause of the landslide of dispersive soil slopes. Figure 8 shows the mineral composition of dispersive soil samples (X-ray diffraction analysis, XRD). The main mineral components in the dispersive soil were quartz (quartz mass ratio: 26.4\%), albite (albite: 28.72\%), potash feldspar (potash feldspar: $28.93 \%$ ), and clay minerals (clay minerals: $9 \%$ ). The albite and potash feldspar in the dispersive soil underwent hydrolysis and carbonation, and the $\mathrm{Na}^{+}$and $\mathrm{K}^{+}$ions in the salt minerals migrated with water to decompose the primary and secondary minerals into clay minerals. The primary minerals in the dispersive soil decomposed and released a large amount of $\mathrm{Na}^{+}$and $\mathrm{K}^{+}$, of which $\mathrm{K}^{+}$was quickly absorbed by plants. It can be seen from the chemical composition of the dispersive soil in Table 7 that the dispersive soil contained a large amount of soluble salts and the content of $\mathrm{Na}^{+}$was considerably higher than the content of the $\mathrm{Ca}^{2+}$ and $\mathrm{Mg}^{2+}$ plasma; therefore, the dispersive soil was strongly alkaline. The dispersive soil particles were combined by monovalent $\mathrm{Na}^{+}$, the ionic force was small, and $\mathrm{Na}^{+}$ was easily taken away under the action of water molecules; the dispersive soil particles were dispersed and dissolved in water because of the hydrological effect. According to the literature, the clay minerals in the nondispersive soil were mainly calcareous montmorillonite, calcareous illite, and kaolinite. The soil was neutral, and the clay particles passed through divalent $\mathrm{Ca}^{2+}$. The ionic force was greater, the water's physical properties were better, and the nondispersive soil did not dissolve in water.

Figure 9 shows a microscopic scanning electron microscopic (SEM) image of the dispersive soil. Most of the minerals were layered. The main mineral components were quartz, feldspar, and clay minerals, and the soil had relatively few pores. 


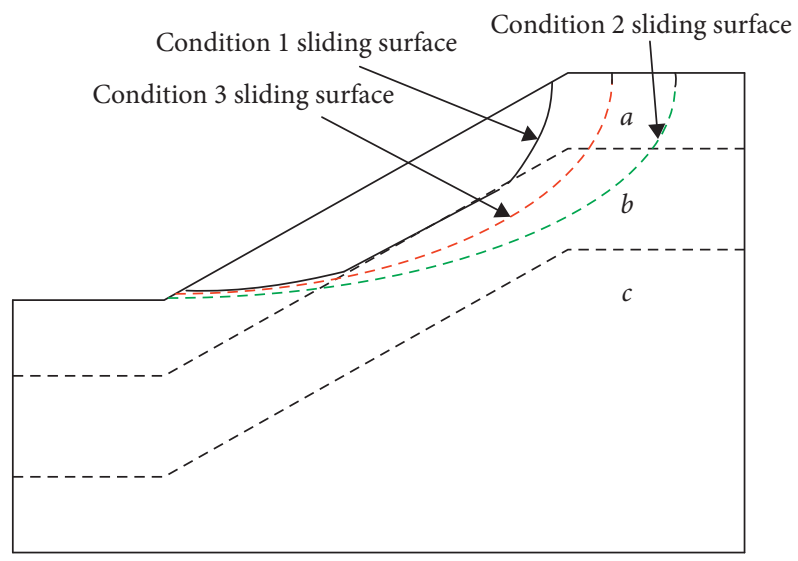

FIGURE 7: The position of the sliding surface.

\subsection{Mechanism of Shallow-Seated Landslides of Dispersive Soil} Slopes. Freeze-thaw is a prerequisite for landslides on dispersive soil slopes. Figure 10 shows the findings of previous research on the characteristics of unsaturated dispersive soil and nondispersive soil of similar grain grades subjected to multiple cycles of freeze-thawing in open systems [23] (with outside water supplementation). The experiments were conducted under the following conditions: cylindrical soil samples with both the diameter and the height being $10 \mathrm{~cm}$, a one-dimensional frost heave, and a thawing settlement caused by the water supplementation, freezing temperature of $-20^{\circ} \mathrm{C}$, and thawing temperature of $20^{\circ} \mathrm{C}$. According to the test results, when the unsaturated dispersive soil underwent freeze-thawing twice, under the water supplementation conditions, the soil mass demonstrated a strong frost heave. The deformation of the soil mass under multiple cycles of freeze-thawing was large and not recoverable, which was entirely distinct from the freeze-thawing characteristics of nondispersive soil. Hence, the dispersive soil showed loose characteristics after freeze-thawing under water supplementation conditions.

The reason for the large and unrecoverable freeze-thaw deformation of the dispersive soil was that the moisture in the dispersive soil transferred the $\mathrm{Na}^{+}$ions in the lower part of the soil sample to the upper part of the soil sample during the freezing process; therefore, the enrichment of $\mathrm{Na}^{+}$in the upper part of the soil sample increased the dispersion of the soil. The soil structure was damaged, and the soil porosity increased, which was more conducive to water migration. During the thawing, as the water was not driven by the temperature change, the downward migration speed was very slow, and the water content of the surface layer of the soil sample was very high, which caused the freeze-thaw deformation of the dispersive soil to gradually increase and the soil could then not be recovered. During the freezing and thawing process of the nondispersive soil, the $\mathrm{Na}^{+}$ content in the soil was very low, the soil structure was not destroyed during the ion migration process, and the water migration speed was very slow; therefore, the freezing and thawing deformation was not large and the soil could basically be restored to the original position after freezing and thawing.
It is believed that irrespective of whether the landslide is shallow or deep, the precondition for the occurrence of landslides is that a large and unrecoverable freeze-thawing deformation must occur in the dispersive soil in an open system (with outside water supplementation), thereby making the dispersive soil loose and susceptible to erosion from the rainfall and the water flow. As shown in Figure 11, although the dispersive soil slope in the Pangtoupao detention basin experienced rainfall and freeze-thawing, which was close to the dispersive soil slopes' landslide of the Zhaolan New River, the slope of the embankment did not undergo landslides, and only some gullies with different depths were formed. The reason was that the groundwater level of the embankment slope in the Pangtoupao detention basin was low. Precipitation mainly occurred in summer, and rainwater evaporated frequently because of the climatic conditions. Hence, the dispersive soil did not have a high internal water content, and the degree of frost heave was small at the low winter temperatures. The temperatures during winter were considerably low, but the dispersive soil slope of the embankment remained dense throughout the season. Rainfall and the drainage of accumulated rainwater only had an erosive effect on the dispersive soil slopes.

According to current research on dispersive soil, it is believed that the difference between dispersive soil and nondispersive soil is mainly in the mineral and chemical composition, and more specifically, in the chemical composition. Zhao and Fan [24] reported that the primary factor affecting the properties of dispersive soil is the chemical composition. Table 6 presents some of the chemical components of dispersive soil in Daqing City. As is observed from this table, dispersive soil contains a large number of sodium ions, which are positively charged and combine with the dispersive soil particles. When the soil mass structure is destroyed by freeze-thawing, the sodium ions are easily dissolved in the water from the effects of saturated soaking and rainfall. Hence, it is believed that the cause of a shallow-seated landslide failure of dispersive soil is that the soil mass generates more pores and cracks during the process of freeze-thawing destruction. Water enters the pores and cracks, and this leads to a substantial reduction of the shear strength of the soil mass. As shown in Figure 12, 


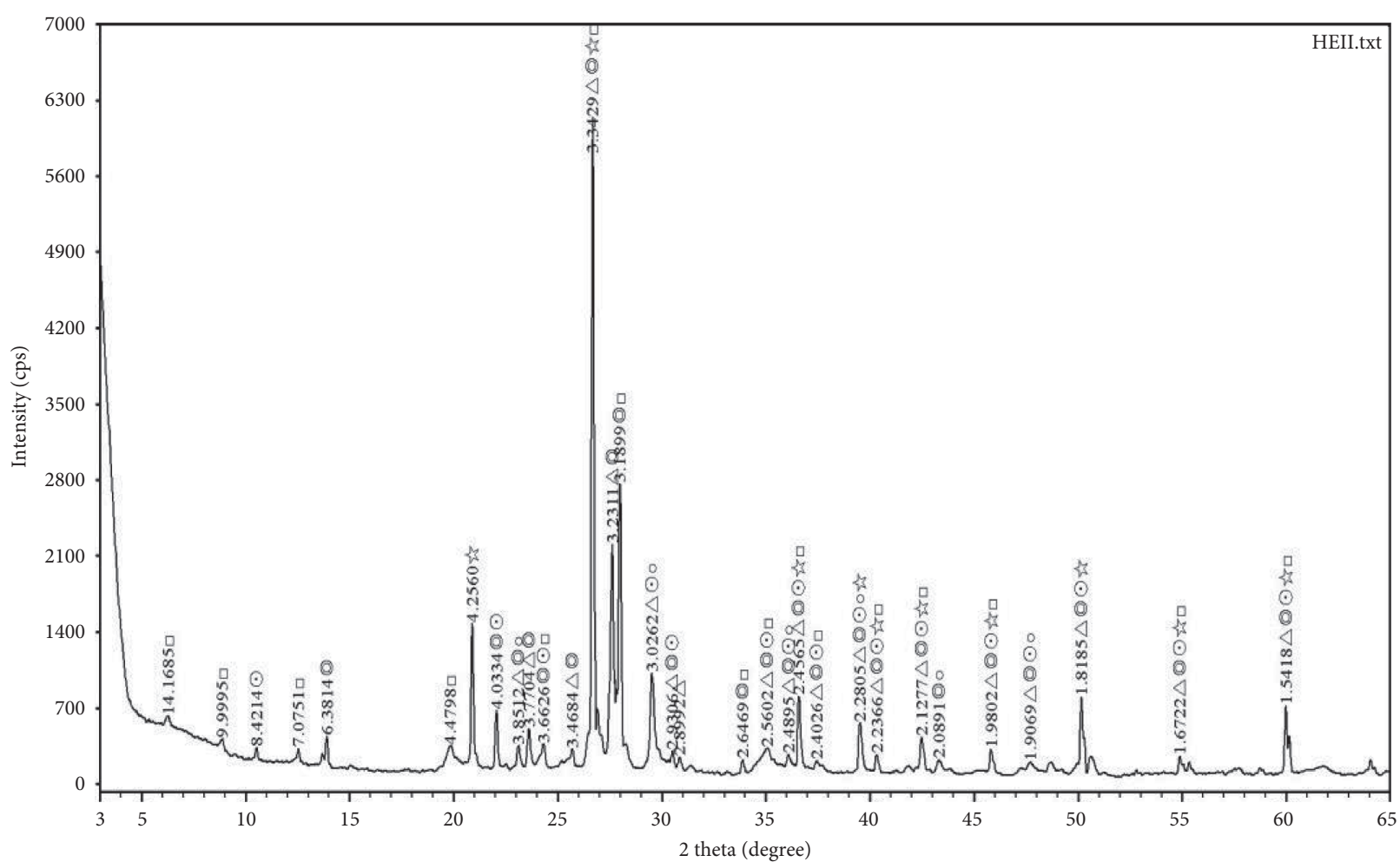

\& PDF 70 - 3755, quartz, $\mathrm{SiO}_{2}: 26.47 \%$

PDF 83 - 0577, calcite, $\mathrm{Ca}\left(\mathrm{CO}_{3}\right): 5.05 \%$

$\odot$ PDF 75 - 0861, tremolite, (Na0.38K0.12Cal.8) $\mathrm{Mg} 4.94 \mathrm{Fe} 0.06$ (A10.2Si7.8)O22:0.43\%
() PDF 70 - 3752, albite, (Na0.98Ca0.02) (A11.02Si2.9808): $28.72 \%$

$\triangle$ PDF 77 - 0135, microcline intermediate, K (Si0.75A10.25)4O8: 28.93\%

$\square$ Clay minerals: $8.40 \%$

FIGURE 8: XRD analysis of dispersive soil sample.

TABle 7: Partial chemical composition content of dispersive soil.

\begin{tabular}{lcccccccc}
\hline & Anion $(\mathrm{mg} / \mathrm{kg})$ & & \multicolumn{3}{c}{ Cation $(\mathrm{mg} / \mathrm{kg})$} \\
$\mathrm{CO}_{3}^{2-}$ & $\mathrm{HCO}_{3}^{-}$ & $\mathrm{CL}^{-}$ & $\mathrm{SO}_{3}^{2-}$ & $\mathrm{Ca}^{2+}$ & $\mathrm{Mg}^{2+}$ & $\mathrm{K}^{+}$ & $\mathrm{Na}^{+}$ & Soluble salt $(\mathrm{mg} / \mathrm{kg})$ \\
\hline 9.5 & 110.1 & 243.2 & 464.0 & 89.8 & 54.4 & 40.1 & 1131.8 & 3815 \\
\hline
\end{tabular}

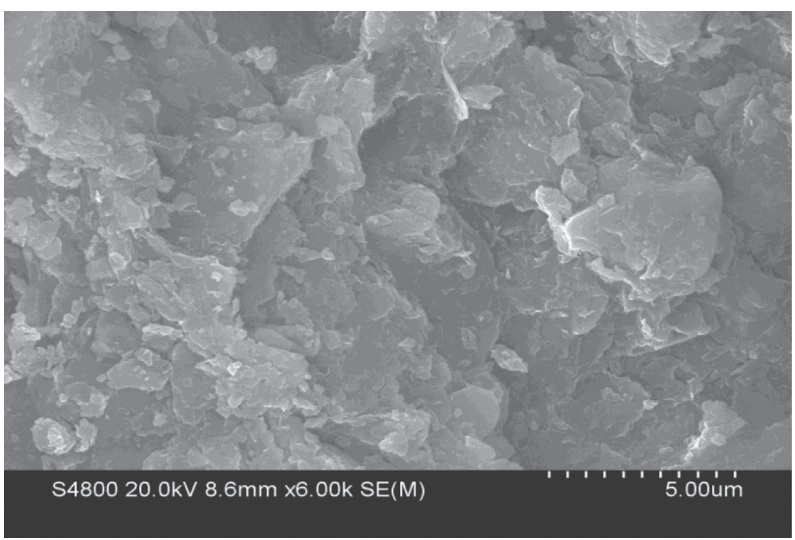

FIgURE 9: SEM micrographs of dispersive soil sample (magnitude =6000).

the compacted dispersive soil after freeze-thawing and soaking was in a muddy state. From the previous tests, it was inferred that the shear strength of the dispersive soil was virtually lost after freeze-thawing and saturated soaking. Increasing the compactness of the soil mass did not improve its shear strength. Therefore, the direct cause of the shallow-seated landslide failure of the dispersive soil was the decrease in the shear strength of the soil mass. From the theoretical calculations of its slope stability, the stability coefficient after freeze-thawing and saturated 


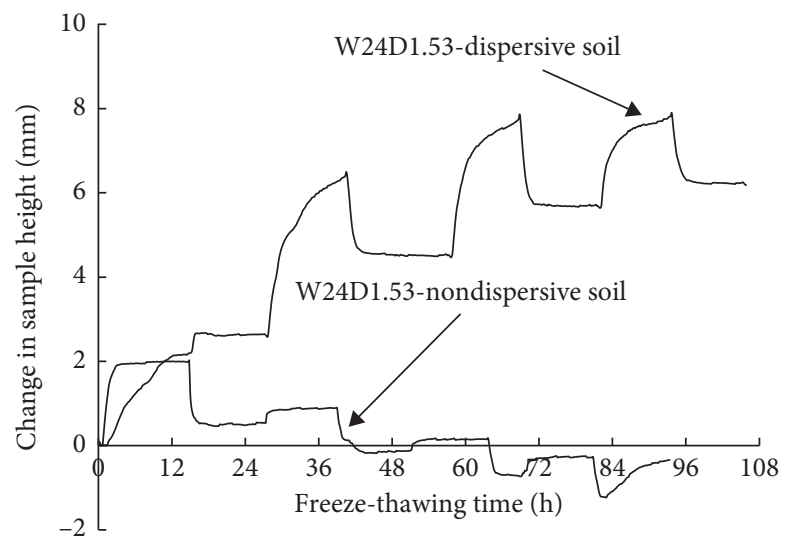

FIGURE 10: Freezing-thawing characteristics of dispersive and nondispersive soil.

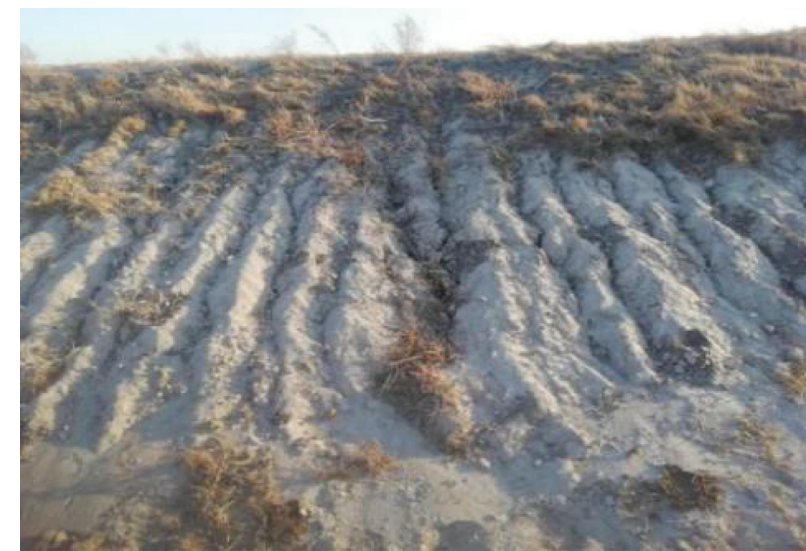

FIgURE 11: Slope erosion of dispersive soil embankment.

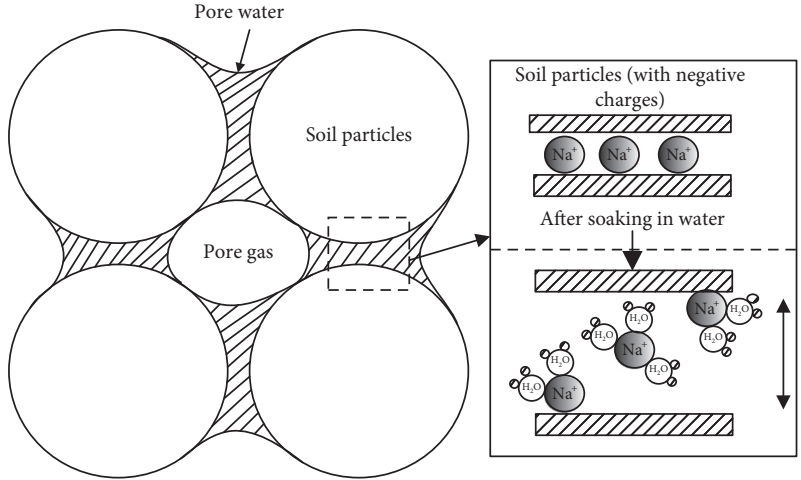

(a)

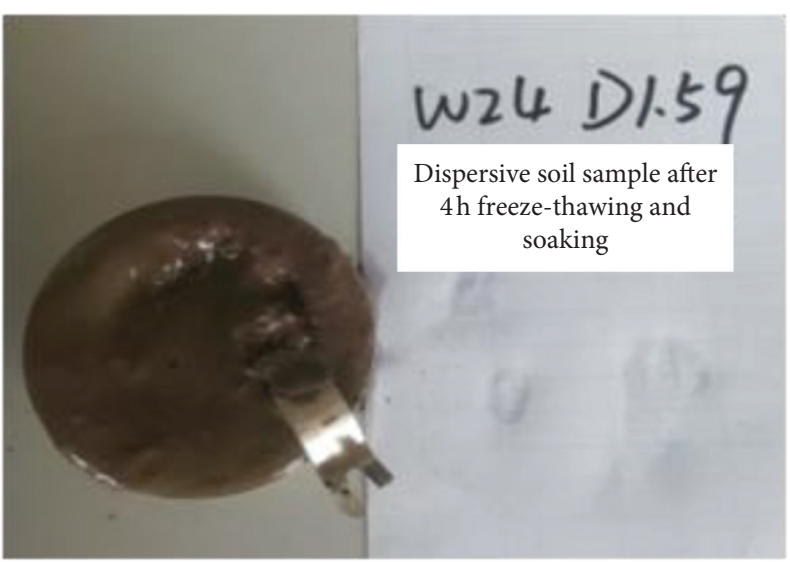

(b)

FIGURE 12: State of dispersive soil after freezing-thawing and soaking. (a) Dispersion mechanism of dispersive soil particles in water after freeze-thawing and soaking and (b) dispersive soil sample state after $4 \mathrm{~h}$ freeze-thawing and soaking.

soaking was considerably lower than the safety coefficient. Hence, the landslide failure occurred.

5.3. Mechanism of Deep-Seated Landslides of Dispersive Soil Slopes. Deep-seated landslides of dispersive soil slopes occurred on the basis of shallow-seated landslides. Freezing and thawing directly led to the formation of shallow-seated landslides and indirectly accelerated the formation of deepseated landslides. Figure 2(b) shows the on-site survey results of the destruction of a dispersive soil slope. It was found that deep-seated landslides were always accompanied by shallow-seated landslides, and shallow-seated landslides 
resulted in the collapse of the dispersive soil slope surface. Hence, numerous tension cracks were generated at the top of the slope, and rainwater entered these cracks and gradually eroded the soil that led to a secondary collapse. Numerous step-shaped landslide bodies appeared on the project site, which eventually propagated through the entire landslide body, culminating in the sliding of the body into the channel. Hence, it was concluded that the deep-seated landslide mechanism of a dispersive soil slope was different from that of the shallow-seated landslide mechanism and had no soaking. It was not an integral landslide, but it was gradually generated through erosion from a shallow-seated landslide.

\section{Conclusions}

The root cause of landslides on dispersive soil slopes in seasonally frozen areas was the particularity of the dispersive soil. Freezing and thawing were the direct causes of dispersive soil in shallow slopes, and it accelerated the formation of deep-seated landslides.

(1) The mineral components of both dispersive soil and nondispersive soil (clay) included feldspar; the dispersive soil mainly consisted of albite and potash feldspar, and the nondispersive soil mainly contained anorthite. The clay minerals in the dispersive soil were combined by sodium ions, and the binding force of the sodium ions was considerably lower than that of the calcium ions. The sodium ions were easily taken away under the action of water molecules, and the soil particles were dispersed in the water.

(2) Dispersive soil landslides in seasonally frozen regions were categorized as shallow-seated landslides and deep-seated landslides. The precondition for generating shallow-seated landslides and deepseated landslides was the occurrence of a large amount of unrecoverable freeze-thawing deformation of the dispersive soil with a water supplementation system, causing loosening and cracks in the soil mass. When the dispersive soil degraded, water rapidly entered the soil mass.

(3) The soil mass was rich in sodium ions. The dissolution of these ions in water destroyed the soil mass structure, resulting in a significant reduction of the shear strength and the bearing capacity, thereby causing shallow-seated landslides. Deepseated landslides resulted from erosion caused by rainfall infiltration after shallow-seated landslides produced tension cracks at the top of the slope.

(4) Freeze-thawing could deteriorate the soil mass structure of the dispersive soil. After freeze-thawing and saturated soaking, the shear strength of dispersive soil was significantly reduced, while the initial dry density and vertical pressure had limited influence on the shear strength of the soil. The shear strength was also considerably low for the highly compacted soil under high vertical pressures. After freeze-thawing, the slope stability coefficient dropped rapidly in the saturated soaking state, which led to landslides. The sliding surface was initiated at the top of the slope and progressed to the bottom along the interface between the soil layers.

\section{Data Availability}

The experimental data, models, and code generated or used during the study are available from the corresponding author upon request.

\section{Conflicts of Interest}

The authors declare that there are no conflicts of interest regarding the publication of this paper.

\section{Acknowledgments}

This investigation was supported by the National Key Research and Development Program of China (grant no. 2017YFC0404805), the Heilongjiang Provincial Natural Science Foundation of China (grant no. ZD2019E009), and the National Natural Science Foundation of China (grant no. 51378164).

\section{References}

[1] X. Z. Long, C. S. Dai, B. Sun, and H. Z. Zhang, "Study on dispersion clay distribution and formation mechanism in songnen plain," Water Resources Planning and Design, vol. 2013, no. 9, pp. 24-27, 2013.

[2] C. A. Vacher, R. J. Loch, and S. R. Raine, Identification and Management of Dispersive Mine Spoils, Australian Centre for Mining Environmental Research, Kenmore, Australia, 2004.

[3] A. Maharaj, "The evaluation of test protocols for dispersive soil identification in southern Africa," Master's thesis, University of Pretoria, Pretoria, South Africa, 2013.

[4] N. Calero, V. Barrón, and J. Torrent, "Water dispersible clay in calcareous soils of southwestern Spain," Catena, vol. 74, no. 1, pp. 22-30, 2008.

[5] C. P. Phillips and D. A. Robinson, "The impact of land use on the credibility of dispersive clay soil in central and southern Italy," Soil Use and Management, vol. 14, no. 3, pp. 155-161, 1998.

[6] H. H. Fan, P. T. Wu, and P. Li, "Study on identification of dispersive clay soil," Chinese Journal of Geotechnical Engineering, vol. 27, no. 11, pp. 1310-1316, 2005.

[7] G. W. Zhao and H. H. Fan, "Study of chemical modification of dispersive clay based on mechanism of dispersive of nondispersive soil," Rock and Soil Mechanics, vol. 34, no. S2, pp. 210-228, 2013.

[8] T. S. Umesh, "Characterization of dispersive soil," Materials Sciences and Applications, vol. 2011, no. 2, pp. 629-633, 2011.

[9] V. R. Ouhadi and A. R. Goodarzi, "Assessment of the stability of a dispersive soil treated by alum," Engineering Geology, vol. 85, no. 1-2, pp. 91-101, 2006.

[10] N. Abbasi, "The use of nanoclay particles for stabilization of dispersive clayey soil," Geotechnical and Geological Engineering, vol. 36, no. 1, pp. 327-335, 2018.

[11] M. Wang, S. Meng, Y. Sun, and H. Fu, "Shear strength of frozen clay under freezing-thawing cycles using triaxial tests," 
Earthquake Engineering and Engineering Vibration, vol. 17, no. 4, pp. 761-769, 2018.

[12] R. L. Shan, Y. W. Song, L. W. Song, and Y. Bai, "Dynamic property tests of frozen red sandstone using a split hopkinson pressure bar," Earthquake Engineering and Engineering Vibration, vol. 18, no. 3, pp. 511-519, 2019.

[13] S. Moravej, G. Habibagahi, E. Nikooee, and A. Niazi, "Stabilization of dispersive soils by means of biological calcite precipitation," Geoderma, vol. 315, pp. 130-137, 2018.

[14] J. L. Sherard, L. P. Dunnigan, and R. S. Decker, "Identification and nature of dispersive soils," International Journal of Rock Mechanics and Mining Sciences \& Geomechanics Abstracts, vol. 102, no. GT4, pp. 287-301, 1976.

[15] N. Abbasi and H. Nazifi, "Assessment and modifification of sherard chemical method for evaluation of dispersion potential of soils," Geotechnical and Geological Engineering, vol. 31, no. 1, pp. 337-346, 2018.

[16] Y. N. Sun, "The studying on the mechanism of beiyin main channel gliding slope," Master's thesis, Northeast Agricultural University, Harbin, China, 2003.

[17] T. Tong, "Analysis and prevention of landslide Yin nen trunk canal in central Hei Longjiang province," Master's thesis, Dalian University of Technology, Dalian, China, 2002.

[18] L. J. Liu, A. S. Su, and B. Zhang, "Study on preventive technology of frost damage on dispersive soil slopge in seasonal frozen area," Heilongjiang Hydraulic Science and Technology, vol. 45, no. 4, pp. 1-8, 2017.

[19] P. Forsythe, "Experiences in identification and treatment of dispersive clays in Mississippi dams," in Dispersive Clays, Related Piping, and Erosion in Geotechnical Projects, J. Sherard and R. Decker, Eds., pp. 135-155, ASTM International, West Conshohocken, PA, USA, 1977.

[20] J. Phillips, "Case histories of repairs and designs for dams built with dispersive clay," in Dispersive Clays, Related Piping, and Erosion in Geotechnical Projects, J. Sherard and R. Decker, Eds., pp. 330-340, ASTM International, West Conshohocken, PA, USA, 1977.

[21] GB/T50123-1999, Standard for Soil Test Method, China Planning Press, Beijing, China, 1999.

[22] G. X. Li, Advanced Soil Mechanics, Tsinghua University Press, Beijing, China, 2016.

[23] L. X. Wang, X. M. Yuan, A. S. Su, and Z. Y. Li, "Experimental study on multiple freeze-thaw properties of unsaturated dispersive clay," Journal of Harbin Institute of Technology, 2020.

[24] G. W. Zhao and H. H. Fan, "Influence of chemical factors on dispersivity of clayey soil and the dispersive mechanism," Journal of Northwest A\&F University, vol. 41, no. 6, pp. 202-206, 2013. 